\title{
Evaporation of water droplets on photoresist surfaces - An experimental study of contact line pinning and evaporation residues
}

Citation for published version (APA):

He, B., \& Darhuber, A. A. (2019). Evaporation of water droplets on photoresist surfaces - An experimental study of contact line pinning and evaporation residues. Colloids and Surfaces A: Physicochemical and Engineering Aspects, 583, [123912]. https://doi.org/10.1016/j.colsurfa.2019.123912

Document license:

CC BY-NC-ND

DOI:

10.1016/j.colsurfa.2019.123912

Document status and date:

Published: 20/12/2019

\section{Document Version:}

Accepted manuscript including changes made at the peer-review stage

\section{Please check the document version of this publication:}

- A submitted manuscript is the version of the article upon submission and before peer-review. There can be important differences between the submitted version and the official published version of record. People interested in the research are advised to contact the author for the final version of the publication, or visit the $\mathrm{DOI}$ to the publisher's website.

- The final author version and the galley proof are versions of the publication after peer review.

- The final published version features the final layout of the paper including the volume, issue and page numbers.

Link to publication

\footnotetext{
General rights

- You may freely distribute the URL identifying the publication in the public portal. follow below link for the End User Agreement:

www.tue.nl/taverne

Take down policy

If you believe that this document breaches copyright please contact us at:

openaccess@tue.nl

providing details and we will investigate your claim.
}

Copyright and moral rights for the publications made accessible in the public portal are retained by the authors and/or other copyright owners and it is a condition of accessing publications that users recognise and abide by the legal requirements associated with these rights.

- Users may download and print one copy of any publication from the public portal for the purpose of private study or research.

- You may not further distribute the material or use it for any profit-making activity or commercial gain

If the publication is distributed under the terms of Article 25fa of the Dutch Copyright Act, indicated by the "Taverne" license above, please 


\title{
Evaporation of water droplets on photoresist surfaces - an experimental study of contact line pinning and evaporation residues
}

\author{
Bojia He and Anton A. Darhuber \\ Department of Applied Physics, Eindhoven University of Technology, \\ P.O. Box 513, 5600MB Eindhoven, The Netherlands
}

(Dated: August 29, 2019)

\begin{abstract}
We have systematically studied the interaction of ultrapure, de-ionized water droplets with chemically-amplified, deep-ultraviolet photoresist layers during evaporation by means of experiments. The contact lines of the evaporating droplets undergo two pinning events. The footprint diameters during pinning $D_{1,2}$ scale with the initial droplet diameter $D_{0}$ approximately as $D_{1,2} \sim D_{0}^{4 / 3}$. Evaporated droplets leave a residue behind, generally in the form of an ultrathin layer (order $1-10 \mathrm{~nm}$ ) with a sub-micron thick mound in the center. We have systematically characterized the residue dimensions as a function of the initial droplet size, the photoresist composition and process conditions. Post-evaporation rinsing steps were found to be unable to completely remove a deposit, depending on how long after droplet evaporation they were performed. Our results indicate that the occurrence of so-called watermark defects might be related to deliquescence induced by ionic residues.
\end{abstract}

Keywords: Evaporation, droplet evaporation, evaporation residues, deliquescence

\section{INTRODUCTION}

Droplets of water or aqueous solutions make contact with partially wettable polymer surfaces in the context of many technological applications, such as coating, printing, cleaning and surface conditioning processes. The modes of interaction of solvent droplets with polymer layers have been studied in detail. ${ }^{1-4}$ Transport can occur inside the polymer matrix by diffusion or outside by evaporation, recondensation or sorption. The polymer material and transport properties typically depend very sensitively on the local solvent concentration. In contrast, the transport properties of hydrophobic polymers depend either not at all or only weakly on the water activity. The water uptake is generally limited to a weight fraction on order of a few percent. ${ }^{5}$ Transport of a non-solvent through a polymer film may occur either through diffusion or bulk flow, depending on the polymer microstructure and the degree of swelling. ${ }^{6}$

In immersion lithography, water droplets come in contact with photoresists (PRs), which are hydrophobic, multicomponent, light-sensitive polymer layers. ${ }^{7-10}$ Some of these droplets evaporate and can induce the formation of so-called watermark defects,,${ }^{9,10}$ which can compromise the yield of semiconductor device manufacturing.

Vogt et al. measured the water concentration depth profile within immersed photoresist films with neutron reflectometry. ${ }^{11}$ For silicon wafers with native oxide layer, they found a pronounced enhancement of the water concentration in a region within the first $2-4 \mathrm{~nm}$ from the PR-substrate interface reaching a water volume fraction of more than $30 \%$ as compared to a bulk value of $2-3 \%$. This is actually a precursor to complete delamination, ${ }^{12}$ if given enough time. For substrates first treated with hexamethyldisilazane (HMDS), a water-enriched layer is still present, ${ }^{11}$ however, with a lower maximum interfacial volume fraction around $15 \%$. The water uptake dy- namics and film thickness increase $\Delta h$ of PR layers upon water immersion has been measured using ellipsometry or the quartz crystal microbalance method. ${ }^{13-15}$ Typical values of $\Delta h$ are in the few percent range. Due to its high static dielectric constant, water readily dissolves polar and dissociating compounds. Photoresist contains typically photoacid generator and quencher species, which are therefore leached out of PR during prolonged contact with water droplets. ${ }^{14,16-22}$ These leached species can be redeposited upon droplet evaporation.

In this manuscript, we report about systematic experiments elucidating the interaction of water droplets with deep-ultraviolet (UV) chemically-amplified photoresist layers during evaporation. Evaporated droplets leave a residue behind, generally in the form of an ultrathin layer (order $10 \mathrm{~nm}$ ) with a (sub)micron thick mound in the center. The ultrathin residue layer thickness depends strongly on the process conditions and PR composition. For PR base polymer layers, which do not contain any leachable components such as quencher, photoacid generator (PAG) and watershedding agent (WSA), it is absent to within our detection limit. We have systematically varied the initial droplet size, the photoresist composition and process conditions and studied their influence on the residue dimensions. Our experimental results compare favourably with a recent theoretical model of residue formation. ${ }^{23}$

\section{MATERIALS \& METHODS}

A commercial, chemically-amplified deep-UV photoresist (PR, JSR) dissolved in a 30/70 mixture (by weight) of cyclohexanone (Sigma-Aldrich, product number C102180) and propyleneglycol-monoethylether-acetate (PGMEA, Sigma-Aldrich, product number 484431), was spin-coated (Brewer Science, model Cee ${ }^{\circledR}$ 
200X) on Si-wafers with a spin speed between 2000 and $6000 \mathrm{rpm}$ for $200 \mathrm{~s}$, which gives a thickness $h$ on order of 60 to $100 \mathrm{~nm}$, respectively. Prediluted PR (1 part PR solution diluted further in 2 parts of pure solvent mixture, by volume) coated at $6000 \mathrm{rpm}$ yields a film thickness of about $20 \mathrm{~nm}$. After spincoating, the samples were baked on a hotplate at a temperature of about $110^{\circ} \mathrm{C}$ for a duration between $5-180 \mathrm{~s}$. All experiments were performed with unexposed resist. Information about its chemical composition is provided in Ref. [40].

For comparison with the complete PR, we also conducted experiments with a solution that only contains the polymer base of the resist, but not any other resist component such as a quencher [triphenylsulfonium salicylic acid (TPSSA)], photoacid generator [PAG, triphenylsulfonium nonaflate (TPSN)], or watershedding agent (WSA). The chemical structures of PAG and quencher are shown in the Supporting Information.

In immersion technology, PR layers are frequently prerinsed prior to lithography. Therefore, we compared samples both with and without pre-rinsing (for either 10 or 120 s using ultrapure deionized (UDI) water) after baking. The pre-rinsed samples were baked for a second time at a temperature of about $110^{\circ} \mathrm{C}$ for a duration of $10-60 \mathrm{~s}$.

UDI water (Millipore Direct-Q3 R, Millipak Express 20 nozzle filter, total organic carbon $\leq 10 \mathrm{ppb}$ ) droplets of varying volume were deposited on the PR layers using an inkjet dispenser head (Microdrop, model number MDK-140, droplet ejection speed about $2 \mathrm{~m} / \mathrm{s}$ ) and left to evaporate in ambient atmosphere with relative humidity about $40 \%$ and temperature of approximately $24^{\circ} \mathrm{C}$ (see Fig. 1). The reservoir container of the inkjet dispenser was made of glass, the tubing of polytetrafluorethylene (PTFE). Each inkjetted droplet has a diameter of about $70 \mu \mathrm{m}$ in air. The deposited droplet volume can be adjusted by accumulating many inkjetted droplets into a bigger droplet with the required volume. The initial footprint diameter of the droplet right after deposition was measured using side-view observation. We did not observe any splashing upon droplet impact, which is consistent with the splashing parameter $K \equiv \mathrm{We} \sqrt{\mathrm{Re}} \approx 20$ defined in Eq. (7) of Ref. [24] being far below the critical value of 3000. Here, We and Re are the Weber and Reynolds number of an impacting droplet, respectively.

We measured the advancing and receding contact angles of water droplets on pre-rinsed PR and non-prerinsed polymer base layers. The results are $\theta_{r}=(63 \pm 2)^{\circ}$ and $\theta_{a}=(88 \pm 2)^{\circ}$ for PR and $\theta_{r}=(63 \pm 2)^{\circ}$ and $\theta_{a}=(78 \pm 2)^{\circ}$ for the polymer base, respectively.

The evaporation of the droplets was monitored using an upright microscope (Olympus, model number BX-51) using Olympus $2.5 \times$ and $10 \times$ objectives. The camera used for recording had a frame rate of $15 \mathrm{~s}^{-1}$. The temperature and the ambient humidity level in the laboratory were $24^{\circ} \mathrm{C}$ and $(40 \pm 10) \%$, respectively.

After recording of the evaporation process by optical microscopy, several samples were post-rinsed by hold-

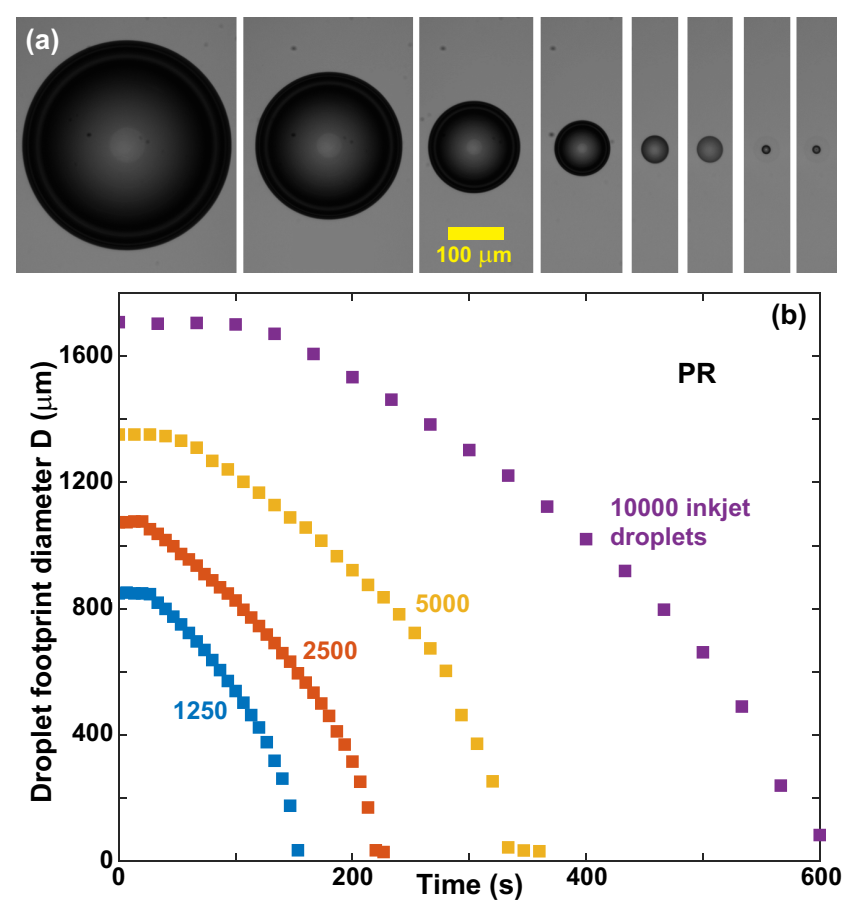

FIG. 1: (a) Image sequence of a water droplet evaporating on a $20 \mathrm{~nm}$ thick PR layer. (b) Droplet footprint diameter $D(t)$ as a function of time for droplets of different volumes evaporating on a $20 \mathrm{~nm}$ thick PR layer.

ing them under the UDI water jet emanating from the faucet of the Millipore dispenser. After such a rinse step, the residues remaining on the samples were characterized by optical microscopy and (after baking for $30-60 \mathrm{~s}$ at $110^{\circ} \mathrm{C}$ ) by means of an atomic force microscope (AFM, Park Scientific, XE7).

\section{EXPERIMENTAL RESULTS}

Figure 1(a) shows a typical image sequence of a droplet evaporating on a $20 \mathrm{~nm}$ thick PR layer. Figure 1(b) shows the droplet footprint diameter $D(t)$ as a function of time for different initial droplet volumes $V_{0}$ evaporating on PR. Equivalent data for polymer base layers is presented in the Supporting Information. Initially, the diameter remains constant for a short while, until the contact angle $\theta(t)$ reaches the receding value. Subsequently, the droplets shrink smoothly and monotonically without pinning until they reach a diameter of about $10 \%$ of the initial value. Very reproducibly, the droplets then tend to get pinned once, temporarily, after which they shrink further by a factor of approximately $2-4$, before they get pinned again. After the second pinning event, the remaining droplets primarily become thinner but do not shrink laterally. A typical late time behavior is shown in Fig. 2. The kink at $\Delta t \approx 1.5 \mathrm{~s}$ indicates the first pinning event. The images in the inset show a few topview images of the evaporating droplet. Note that the 


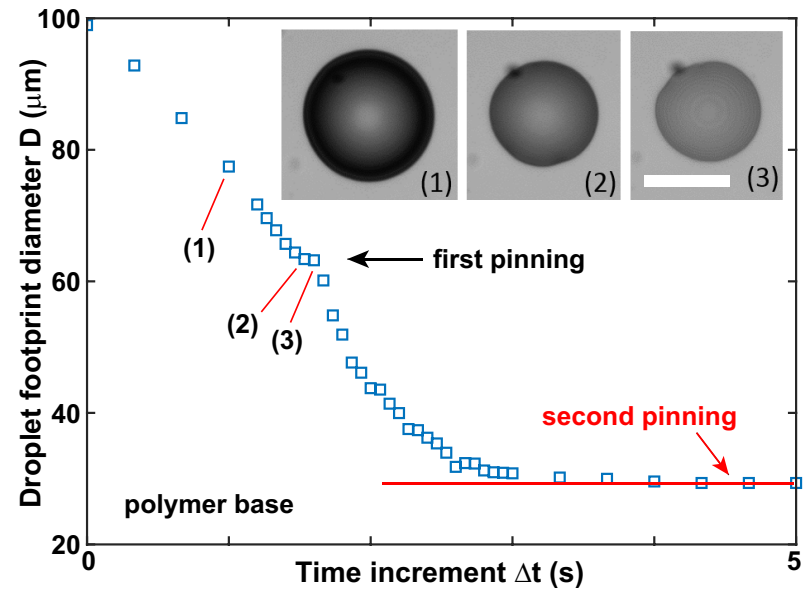

FIG. 2: Late-time evolution of the droplet footprint diameter approaching complete evaporation on a $20 \mathrm{~nm}$ thick polymer base layer (non-pre-rinsed). The initial droplet diameter was about $800 \mu \mathrm{m}$. Inset: droplet images corresponding to the three labeled datapoints. The white scalebar corresponds to $50 \mu \mathrm{m}$.

grayscale at the droplet perimeter is very dark in image (1), whereas it becomes much lighter in image (3). This indicates that the contact angle significantly decreases during the pinning phase, while the droplet diameter remains unchanged between frames (2) and (3). For late times $\Delta t>3 \mathrm{~s}$, the droplet diameter remains approximately constant (second pinning). The data for PR look qualitatively identical to those shown in Fig. 2. We denote the droplet diameter at the first pinning event $D_{1}$, at the second pinning event $D_{2}$. Given that about 10 interference fringes are visible in inset (3) of Fig. 2 and that $D_{1} \approx 60 \mu \mathrm{m}$, we estimate the value of the contact angle at depinning to be about $9^{\circ}$.

Figure 3(a-f) shows microscope images of dried deposits from droplets with different initial sizes $D_{0}$ evaporated on a PR layer. In Fig. 3(i) we present the dependence of the pinning diameters $D_{1}$ and $D_{2}$ on the initial droplet diameter $D_{0}$. The dashed lines are power law relations $D_{i} \sim D_{0}^{4 / 3}$. The data for $D_{1}$ and $D_{2}$ differ by a roughly constant factor of about 4 . Figures $3(\mathrm{a}, \mathrm{b})$ in the Supporting Information provide equivalent data obtained with a different grade of UDI water.

For small initial droplet sizes $D_{0}$, the dependence of $D_{1,2}$ on $D_{0}$ in Fig. 3(i) becomes weaker as indicated by the light red background color. From side-view observations, we noted a significant difference in the initial contact angle $\theta_{0}$, which was smaller for smaller droplets (see Fig. 4). The values of $\theta_{0}$ span roughly the range from $\theta_{r}$ to $\theta_{a}$, which is a consequence of the inkjet deposition process. If only very few inkjet droplets are accumulated, the kinetic energy addition by the last accumulated droplet causes a significant transient increase of the footprint diameter and corresponding flattening of the droplet shape. This leads to a subsequent contact line retraction that leaves the contact angle close to

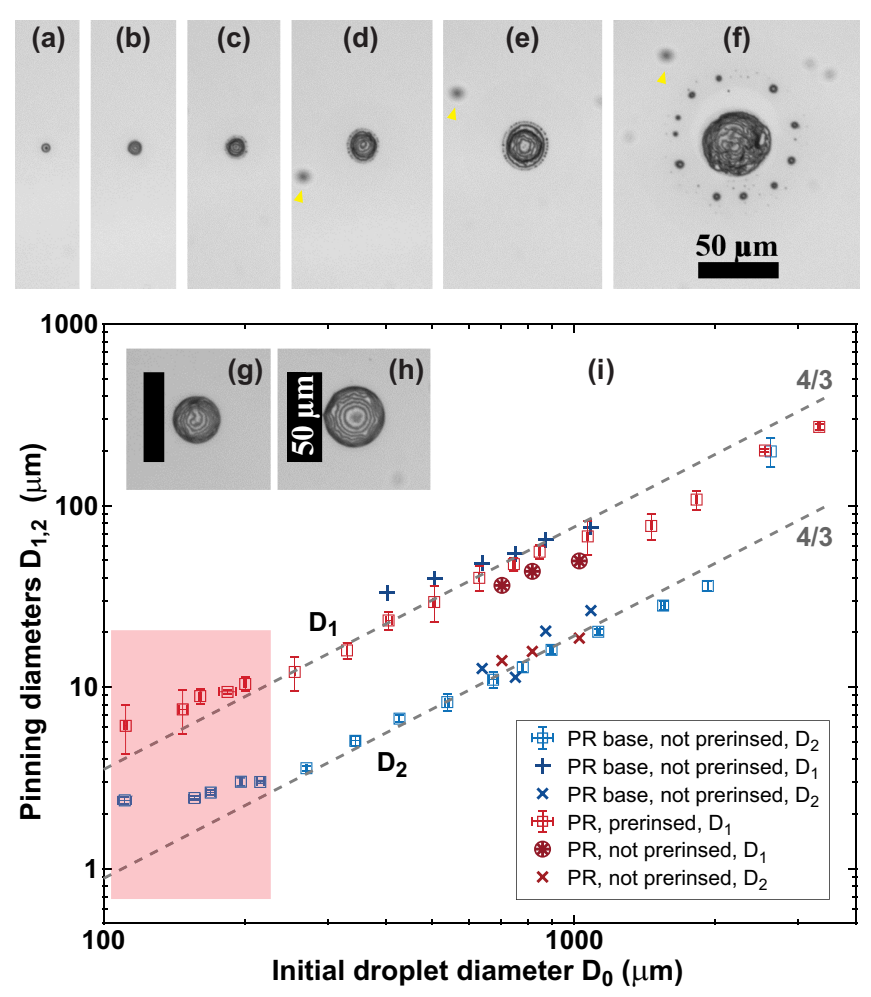

FIG. 3: (a-f) Microscope images of deposits from droplets with different initial sizes $D_{0} \approx 200$ (a), 400 (b), 630 (c), 840 (d) 1800 (e) and $3300 \mu \mathrm{m}$ (f) evaporated on a $20 \mathrm{~nm}$ thick PR layer. The fuzzy spots that are visible in $(\mathrm{d}, \mathrm{e}, \mathrm{f})$ and marked with yellow triangles are due to contamination on the microscope optics. $(\mathrm{g}, \mathrm{h})$ Images of deposits from droplets with different initial sizes $D_{0} \approx 1540(\mathrm{~g})$ and $1930 \mu \mathrm{m}(\mathrm{h})$ evaporated on a $20 \mathrm{~nm}$ thick polymer base layer. (i) Correlation of the pinning diameters $D_{1}$ (first pinning) and $D_{2}$ (second pinning) with initial droplet sizes on PR and polymer base layers. Squares correspond to data extracted from dried residue images as shown in (a-f). The other symbols represent data extracted from video recordings of the entire evaporation process.

its receding value. However, if a large number of inkjet droplets are accumulated, the addition of a single one does not cause a noticeable shape change. Rather, the slowly increasing drop volume causes the contact angle to be close to its advancing value. The transient increase of the droplet footprint for small volumes implies that the droplet is in contact with a relatively larger surface area of the underlying layer, from which relatively more material can be leached. This is the likely reason for the flattening of the dependence $D_{1,2}\left(D_{0}\right)$ for small $D_{0}$ in Fig. 3(i).

The effect of process conditions on the first and second pinning diameters is illustrated in Fig. 5. Figures 5(ad) and (e-h) compare droplets deposited on rinsed and non-rinsed $20 \mathrm{~nm}$ thick PR layers. Figures 5(i-l) were obtained for a thicker PR layer of $h=100 \mathrm{~nm}$. Figures $5(\mathrm{~m}-$ p) correspond to a polymer base layer. All samples were baked for $30 \mathrm{~s}$ after spin-coating. Rinsed samples were 


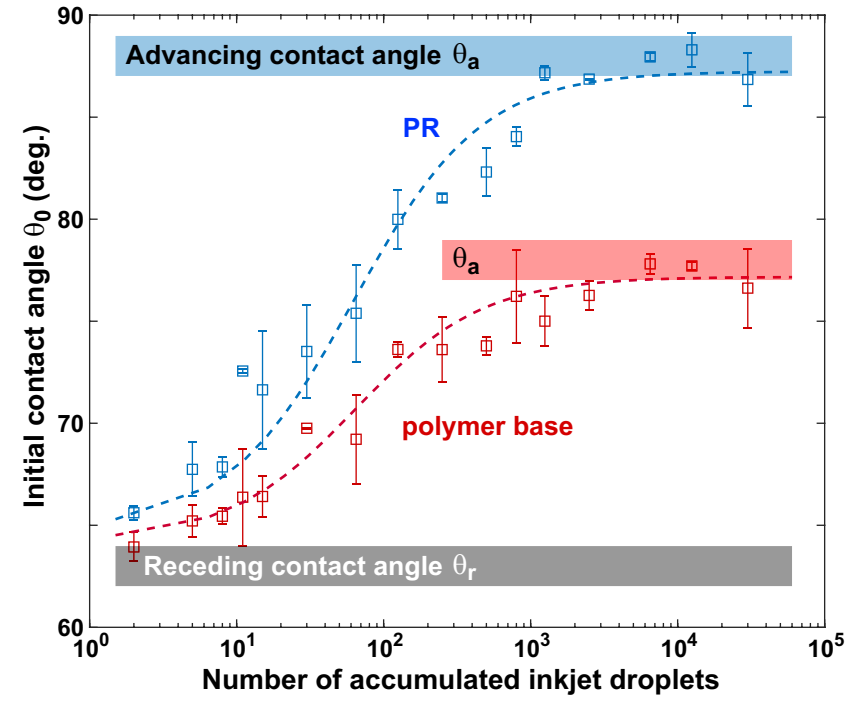

FIG. 4: Initial contact angle $\theta_{0}$ of deposited droplets as a function of the number of accumulated inkjetted droplets for PR and polymer base layers, respectively. The solid horizontal lines indicate the advancing and receding contact angle values. The dashed lines are guides to the eye.

baked for an additional $30 \mathrm{~s}$. Panels (a,b), (e,f), (i,j) and $(\mathrm{m}, \mathrm{n})$ approximately correspond to the first pinning phase, where a pronounced decrease in contact angle is visible, as indicated by the change in grayscale inside the droplet, whereas the footprint radius remains roughly constant.

For droplets evaporating on PR layers, the first pinning leaves a visible trace in subsequent images. A 'halo' with diameter $D_{1}$ is observed around the residual droplets of diameter $D_{2}$ in Fig. $5(\mathrm{c}, \mathrm{g}, \mathrm{k})$ for PR layers. However, no such halo is observed for polymer base layers in Fig. 5(o). A comparison of Figs. 5(c,k) shows that the PR layer thickness does not affect the magnitude of $D_{1,2}$ strongly. However, the perimeter of the halo is more pronounced and easier to see for the thicker layer, even without contrast enhancement. The baking time does not have a strong effect on $D_{1,2}$ as shown in Fig. 6. This suggests that the residual solvent level in the PR layer ${ }^{25}$ does not impact the pinning.

To further characterize the interaction between evaporation residues (consisting of a halo and a center deposit) and PR layers, we conducted post-evaporation rinsing experiments. During the post-rinsing step, samples were held under the UDI water jet emanating from the faucet of the Millipore system for $5 \mathrm{~s}$. Figure 7 shows droplet evaporation residues on three samples before and after post-rinsing. All samples were initially spin-coated with PR layers with a thickness of about $100 \mathrm{~nm}$ and baked at $110^{\circ} \mathrm{C}$ for $30 \mathrm{~s}$. Samples I [Figure $7(\mathrm{a}-\mathrm{c})$ ] and II [Figure $7(\mathrm{~d}-\mathrm{f})]$ were pre-rinsed with UDI-water for $10 \mathrm{~s}$ and baked a second time at $110^{\circ} \mathrm{C}$ for 30 s while sample III [Figure $7(\mathrm{~g}-\mathrm{i})$ ] was not pre-rinsed and baked only once. Droplets with initial diameter of about $1000 \mu \mathrm{m}$ were de-
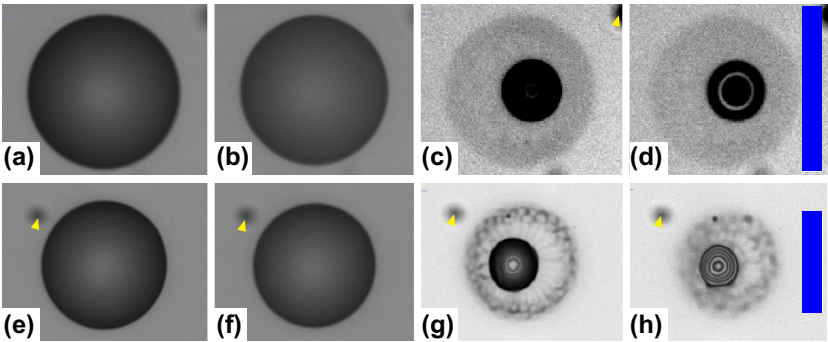

(e)
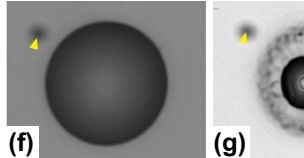

(g)
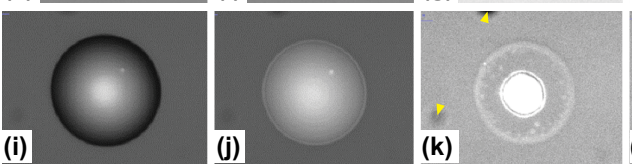

(h)
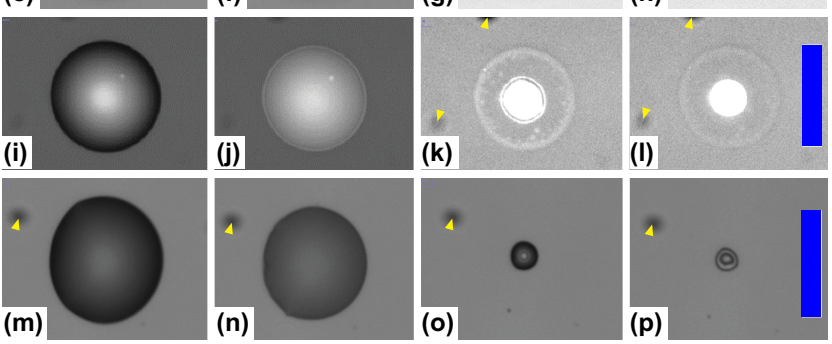

FIG. 5: Microscope images for layers of (a-d) $20 \mathrm{~nm}$ thick prerinsed PR, (e-h) $20 \mathrm{~nm}$ thick non-pre-rinsed PR, (i-l) $100 \mathrm{~nm}$ thick pre-rinsed PR and (m-p) $20 \mathrm{~nm}$ thick non-pre-rinsed base polymer. Panels $(\mathrm{c}, \mathrm{d}),(\mathrm{g}, \mathrm{h})$ and $(\mathrm{k}, \mathrm{l})$ have been contrastenhanced. The time increment of frames $(\mathrm{d}, \mathrm{h}, \mathrm{l})$ relative to $(\mathrm{c}, \mathrm{g}, \mathrm{k})$ were $6.8,7.9$ and $5.2 \mathrm{~s}$, respectively, whereas the time increment from (g) relative to (f) was only $0.8 \mathrm{~s}$. All scale bars correspond to $50 \mu \mathrm{m}$. The fuzzy spots that are visible in many images and marked with yellow triangles are due to contamination on the microscope optics. The initial diameter $D_{0}$ ranged between about 750 and $1000 \mu \mathrm{m}$ in all cases.
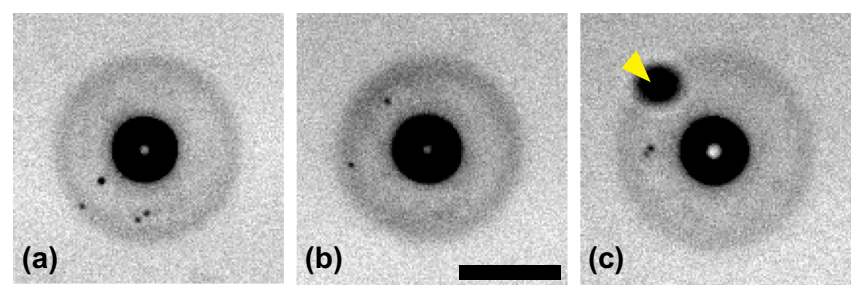

FIG. 6: Contrast-enhanced microscope images of the late stage of the evaporation process on PR (rinsed for $10 \mathrm{~s}$ ) after the first pinning for different total baking times of (a) 15, (b) 60 and (c) $240 \mathrm{~s}$. The scalebar in (b) corresponds to $25 \mu \mathrm{m}$ and applies to all panels.

posited on the samples.

Figures $7(\mathrm{a}, \mathrm{b})$ show the residue on sample I before and 5 minutes after post-rinsing, respectively. Figure $7(\mathrm{c})$ is a zoom of Fig. 7(b). Figures 7(d,e) show the residue on sample II 5 minutes and 24 hours after droplet evaporation, respectively. Figure 7(f) shows sample II 24 hours after post-rinsing. Figures 7 (g-i) show a residue on sample III before, 5 minutes after and 24 hours after postrinsing, respectively. Figure 8 shows an AFM area scan and a cross-section through the center of the deposit visible in Fig. 7(f). 

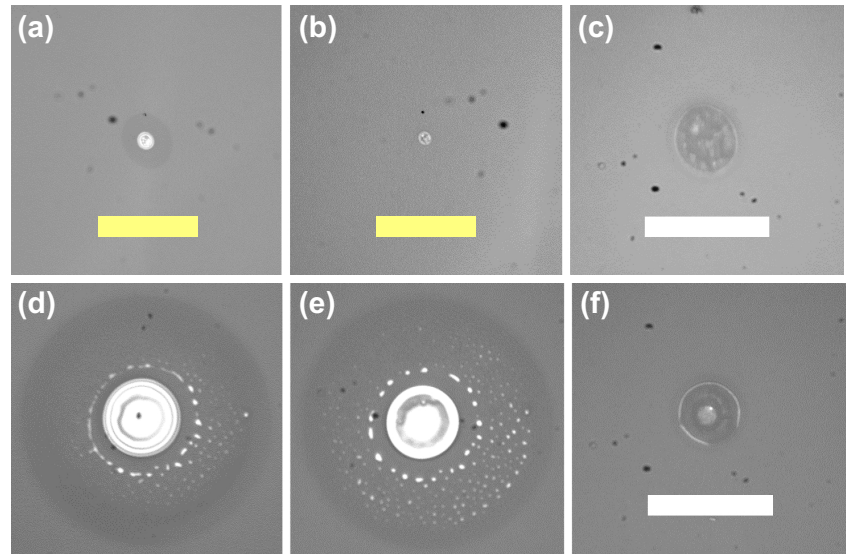

(f)
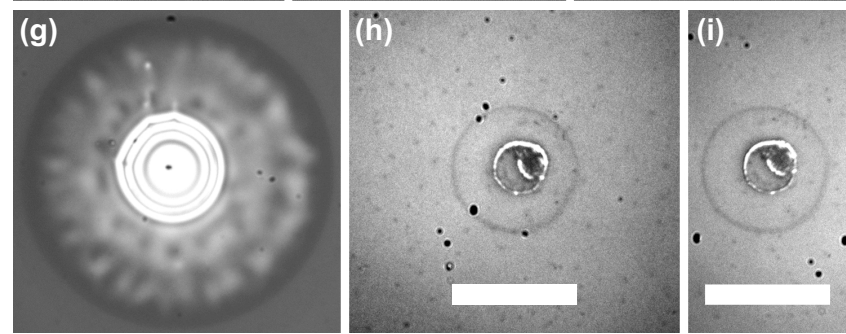

FIG. 7: Contrast-enhanced microscope images of the evaporation residues on PR layers before (a,d,e,g) and after (b,c,f,h,i) a post-rinsing step. The scale bars in (a,b) represent $100 \mu \mathrm{m}$, all other scale bars $25 \mu \mathrm{m}$. The scalebar in (f) also applies to $(\mathrm{d}, \mathrm{e}, \mathrm{g})$.

\section{DISCUSSION}

The most striking experimental finding is the observation of the halos on PR layers, which are absent on the polymer base layers. Nakagawa et al. have observed a similar phenomenon. ${ }^{26}$ Interestingly, the halos of both the non-pre-rinsed layer in Fig. $5(\mathrm{~g}, \mathrm{~h})$ and the $100 \mathrm{~nm}$ thick layer in Fig. $5(\mathrm{k}, \mathrm{l})$ exhibit a marked change in appearance in the course of several seconds. This could be due to water that has diffused into the polymer bulk ${ }^{27,28}$ and slowly evaporates again or due to the presence of an ultrathin layer of low volatility on top of the photoresist. Park et al. studied the evaporation of UDI water droplets on Teflon AF layers spin-coated onto glass substrates. ${ }^{29}$ Using scanning electron microscopy (SEM) instead of optical interferometry they observed a halo, which coincided with the entire initial droplet footprint and which may thus be a precursor to delamination. ${ }^{12}$ In our case, however, since the contact time with the water droplet of a point beyond $D_{1}$ just outside the halo and a point within $D_{1}$ just inside the halo are similar, it is unlikely that water diffusion into the polymer is the origin of the effect.

The terminal phase of the evaporation process after the first pinning is likely dominated by the increasing concentrations of leached compounds such as the quencher, PAG, WSA, polymer fragments and residual solvents. These might lead to a gradual but substantial and spa-
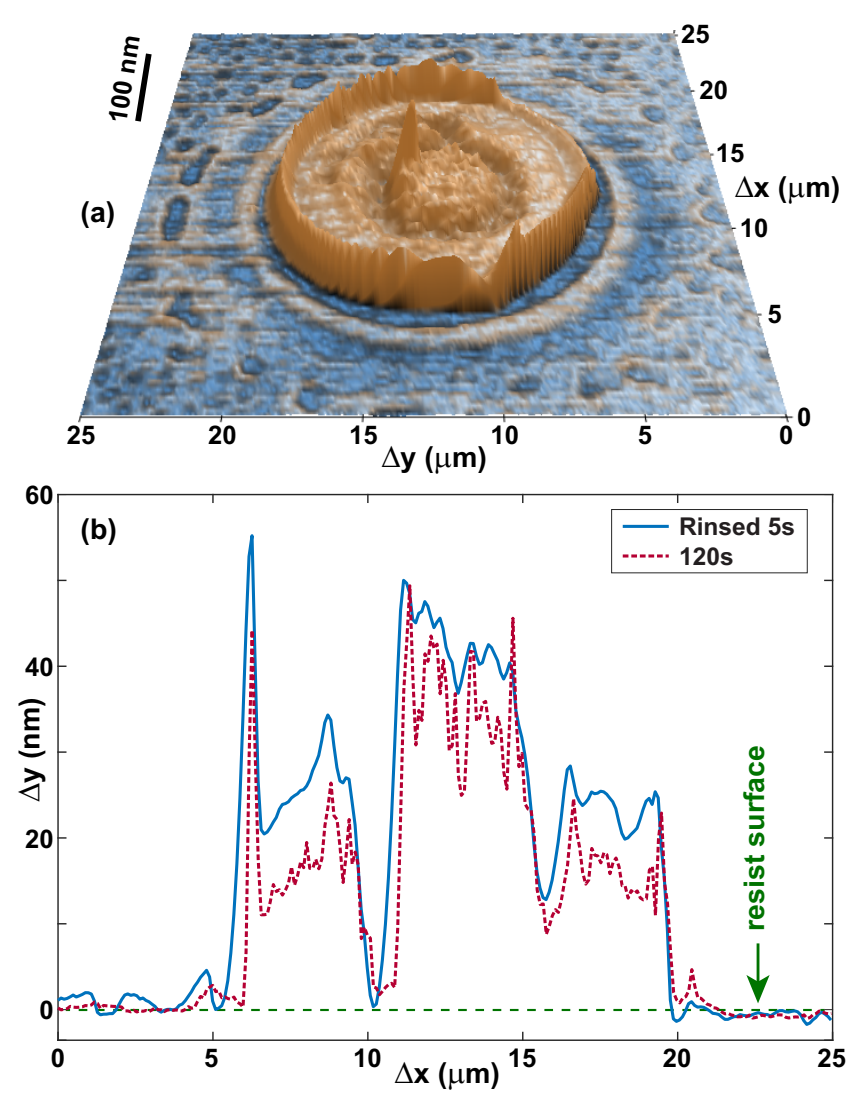

FIG. 8: AFM area scan (a) and 1D cross-section through the center (b) of the residue remaining after post-rinsing of $5 \mathrm{~s}$ shown in Fig. 7(f) (blue solid line) and after an additional post-rinsing step of $120 \mathrm{~s}$ (red dashed line, see supporting information).

tially inhomogeneous surface tension reduction as well as a viscosity increase. The regular spoke-like structure of the halo in Fig. $5(\mathrm{~g}, \mathrm{~h})$ is indeed reminiscent of patterns observed for evaporation-related Marangoni instabilities (see e.g. Fig. 4 in the supporting information, Fig. 3 in Ref. [30] or Figs. 3 and 5 in Ref. [31]) and/or in drying suspensions (see e.g. Fig. 5 in Ref. [32] or Fig. 2(a) in Ref. [33]).

However, the stage prior to the first pinning is characterized by perfectly smooth, circular drop shapes and rapid evaporation rates, such that the enrichment of leached material likely does not yet affect the average viscosity significantly. For the same reason, a pinning mechanism based on suspended particles ${ }^{34}$ seems unlikely. However, the evaporation rate of a droplet is spatially highly non-uniform and exhibits a sharp peak at the contact-line $^{35}$ for contact angles below $90^{\circ}$. It is thus conceivable that within a submicron distance from the contact line the concentration of e.g. the leached quencher or PAG ions either exceed their solubility limit ${ }^{23}$ or induce a significant localized viscosity increase. Both alternatives could induce a temporary pinning of the contact line, until the contact angle has dropped sufficiently, such that depinning occurs. ${ }^{36}$ 
A detailed model for such a precipitation mechanism underlying the first pinning event is presented in Ref. [23]. The prediction for the case of slow leaching of material out of the PR layer compared to the evaporation timescale is that $D_{1}$ should scale as $D_{0}^{4 / 3}$. In case the UDI water is not entirely clean, the exponent is expected to lie between $4 / 3$ and 1 . The experimental data in Fig. 3 agree very well with a powerlaw relation $D_{1} \sim D_{0}^{\alpha}$ with exponent $\alpha$ close to $4 / 3$. What this model cannot fully explain, however, is why the $D_{1}$ data for both PR and polymer base are rather similar and why the pre-rinsing does not seem to make a large difference, although these conditions clearly affect the quantity of leached material.

We believe that the halo formation after the first pinning is akin to a coating process, ${ }^{37,38}$ where a thin deposit film is left behind by a receding solution meniscus. According to Fig. 2, a typical speed of recession is $25 \mu \mathrm{m} / \mathrm{s}$. The major part of the leached material ends up in the central residual spot. We have measured the thickness of the halo layer and the center mound for a pre-rinsed, $100 \mathrm{~nm}$ thick PR sample after baking at $110^{\circ} \mathrm{C}$ for $60 \mathrm{~s}$ using AFM (see Fig. 5 in the Supporting Information) to be about 2 and $600 \mathrm{~nm}$, respectively, for $D_{0} \approx(900 \pm 100) \mu \mathrm{m}$. If $D_{1}$ is estimated as $7 \%$ of $D_{0}$, then this accumulated material would imply a resist thickness reduction of order $0.1 \mathrm{~nm}$ upon contact with water, averaged over the initial contact area with diameter $D_{0}$. For comparison, Conley et al. measured a thickness loss of approximately $0.3-0.5 \mathrm{~nm}$ due to PAG leaching. ${ }^{39}$ Moreover, He and Darhuber detected a significant amount of quencher leaching for the resist used in this study. ${ }^{40}$

Figures $7(b, f)$ indicate that the halo is removed by post-rinsing, but the center of the deposit is largely retained. The AFM scans shown in Fig. 8 indicate that these features are most likely incompletely removed deposit. Also longer post-rinsing times $(2-3 \mathrm{~min})$ did not lead to complete removal of the remaining deposits [see Fig. 8(b) and the Supporting Information for more details]. The residue on sample II was left for 24 hours before post-rinsing. The presence of interference fringes in Figs. 7(d,e) indicates that the residue is still liquidlike. Figure 7(d) exhibits more fringes than (e), which indicates continued evaporation, however, at a very slow rate. The residue on sample III (without pre-rinse) is thicker compared to samples I and II, which means more materials from the PR-layer was collected by the droplet during its evaporation and deposited inhomogeneously after the first pinning of the contact line. Similar to Fig. 7(f), the halo was removed after post-rinsing and structures appeared within the central liquid-like deposit that was visible before post-rinsing.

\section{Relevance to technological applications}

Contact between PR and water in general does not cause watermark defects, as it is common to pre- rinse or post-rinse wafers before or after certain process steps. ${ }^{41-43}$ Kawamura et al. showed that no watermark defects occur, if droplets are removed by airjet blowing before complete evaporation, which indicates that the terminal phase of the evaporation process is the detrimental one. ${ }^{44}$ Near complete evaporation, any dissolved components that have been leached from the photoresist ${ }^{15-17,19,45,46}$ during the lifetime of the droplet are strongly enriched in concentration. Ishibashi et al. performed a TOF-SIMS analysis of the drying residues of water droplets on immersion resists and found a significant enhancement of the PAG concentration. ${ }^{47}$ Farys et al. showed that the PAG anion leaching decreases by a factor 2 for an increase of the soft-baking temperature from $90^{\circ} \mathrm{C}$ to $130^{\circ} \mathrm{C}$, whereas the defect density remained constant. $^{48}$

Kanna et al. performed quartz crystal microbalance measurements of the water uptake by photoresist at different temperatures and found that higher temperatures drastically enhance water uptake. ${ }^{14}$ They concluded that droplets that are sufficiently large such that they do not fully evaporate before the wafer undergoes the postexposure bake (PEB) are highly likely to induce watermark defects. Streefkerk et al. presented a linear correlation between watermark defect size and initial droplet size and found that there is a critical droplet size, below which no watermark defects are formed. ${ }^{41}$ Wallraff observed residue sizes close to $5-10 \%$ of the initial drop size. ${ }^{49}$

We observed that the overall evaporation rate drastically decreases in the last phase of the lifetime of a droplet, see e.g. Fig. 5. We attribute this effect to the continued enrichment of non-volatile ionic compounds in the remaining droplet due to loss of water. Consequently, according to Raoult's law, ${ }^{50}$ the vapor pressure and thus the evaporation rate $\dot{m}$ significantly decreases. ${ }^{51-55}$ The vapor pressure may even approach the ambient humidity level, at which point evaporation stops. Conversely, under such circumstances ambient humidity may condense onto dry deposits, ${ }^{56}$ which is known as deliquescence. ${ }^{57-59}$ Mixtures of solutes further lower the critical humidity levels, at which water uptake occurs. ${ }^{58,60}$

This is especially relevant to the environment inside immersion lithography machines, where the local humidity levels might be higher compared to typical production facility levels. ${ }^{61,62}$ The lowering of both the vapor pressure and the deliquescence threshold enhances the probability of wet residue to enter the PEB process, where the increased temperatures enhance the water penetration in the underlying resist. ${ }^{14}$ The presence of water may in turn enhance the diffusion of e.g. the quencher or the photoacid. It may cause increased leaching or, conversely, mass transfer from the wet residue into the top of the resist. ${ }^{23}$ The smoothness of the thin film interference fringe pattern in Fig. 3(h), which has been recorded approximately 30-60 minutes after the evaporation process was apparently complete, indicates that a significant frac- 
tion of water might still be present in the deposit. The same conclusion was drawn from Figs. $7(\mathrm{~d}, \mathrm{e})$.

Frequently, post-rinsing steps are performed in order to reduce the watermark defect density. ${ }^{41,63,64}$ Our results in Fig. 7 show that the evaporation residues may not be completely removed by a short post-rinse step. This is consistent with the results of Kocsis et al., who showed that a post-rinse step must be performed sooner rather than later for it to be effective in reducing watermark defects. $^{9,65}$ In this fashion part of the original residues might still enter the elevated temperatures during the PEB process.

\section{SUMMARY AND CONCLUSIONS}

We have systematically studied the interaction of ultrapure, de-ionized water droplets with deep-ultraviolet photoresist layers during evaporation by means of experiments. For approximately $90 \%$ of the drying time, the droplet contact line maintains a circular shape and smoothly recedes without stick-slip behavior. At a diameter $D_{1}$ on order of $5-10 \%$ of the initial drop diameter, a first transient pinning event is observed, after which the contact line continues to recede. A comparison of the dependence $D_{1}\left(D_{0}\right)$ with a theoretical model based on precipitation-induced pinning is very favorable.

Depending on the PR composition, an ultrathin residual layer with a thickness on order of $1-10 \mathrm{~nm}$ is observed within the droplet footprint of the first pinning for pre-rinsed layers. This residue tends to be thicker for non-pre-rinsed layers and absent for layers that only contain the photoresist base polymer, but not any leachable components such as quencher, photoacid generator and watershedding agent. Therefore, the residue likely consists of leached, ionic and non-ionic photoresist components. We have systematically characterized the residue dimensions $D_{1}$ as a function of the initial droplet size $D_{0}$, the photoresist composition and process conditions. We found that to good approximation the scaling $D_{1} \sim D_{0}^{4 / 3}$ holds, in excellent agreement with a recent theoretical model for the evaporation of droplets that interact with their sublayer. Post-evaporation rinsing steps were found to be unable to completely remove a deposit, depending on how long after droplet evaporation they were performed.

Ionic compounds such as the quencher and photoacid(generator) are known to induce deliquescence in sufficiently humid environments. Therefore, we suspect that the root cause of watermark defects might be a sufficient quantity of water remaining on a wafer sufficiently long for it to enter the post-exposure bake process. There the combination of increased temperatures and the presence of liquid-phase water vastly enhance diffusive transport inside as well as in and out of an exposed photoresist layer.

\section{Acknowledgements}

This research is part of the research program Towards zero defectivity with project number 13919, which is (partly) financed by the Netherlands Organisation for Scientific Research (NWO). We are grateful to Wim Schollaert of JSR Micro for providing the photoresist samples.
1 A. Tay, D. Bendejacq, C. Monteux and F. Lequeux, 'How does water wet a hydrosoluble substrate?,' Soft Matter, 7, 6953 (2011).

2 J. Dupas, E. Verneuil, M. Ramaioli, L. Forny, L. Talini, and F. Lequeux 'Dynamic Wetting on a Thin Film of Soluble Polymer: Effects of Nonlinearities in the Sorption Isotherm,' Langmuir 29, 12572-12578 (2013).

3 J. Dupas, E. Verneuil, M. Van Landeghem, B. Bresson, L. Forny, M. Ramaioli, F. Lequeux, and L. Talini 'Glass Transition Accelerates the Spreading of Polar Solvents on a Soluble Polymer,' Phys. Rev. Lett. 112, 188302 (2014).

${ }^{4}$ F. Lequeux, L. Talini, E. Verneuil, G. Delannoy, and P. Valois, 'Wetting of polymers by their solvents,' Eur. Phys. J. E 39, 12 (2016).

5 O. Rodriguez, F. Fornasiero, A. Arce, C. J. Radke, and J. M. Prausnitz, 'Solubilities and diffusivities of water vapor in poly(methylmethacrylate), poly(2hydroxyethylmethacrylate), poly(N-vinyl-2-pyrrolidone) and poly(acrylonitrile),' Polymer 44, 6323-6333 (2003).

${ }^{6}$ H. Yasuda and A. Peterlin, 'Diffusive and Bulk Flow Transport in Polymers,' J. Appl. Polymer Sci. 17, 433-442 (1973).

7 M. Switkes and M. Rothschild, 'Resolution Enhancement of $157 \mathrm{~nm}$ Lithography by Liquid Immersion,' J. Microlithography, Microfabrication, Microsystems 1, 225-228 (2002).

8 R. H. French and H. V. Tran, 'Immersion Lithography: Photomask and Wafer-Level Materials,' Annu. Rev. Mater. Res. 39, 93-126 (2009).

${ }^{9}$ Y. Wei and R. L. Brainard, 'Advanced Processes for 193nm Immersion Lithography,' SPIE Press (Bellingham, WA, 2009)

10 D. P. Sanders, 'Advances in Patterning Materials for 193 nm Immersion Lithography,' Chem. Rev. 110, 321-360 (2010).

11 B. D. Vogt, C. L. Soles, C.-Y. Wang, V. M. Prabhu, P. M. McGuiggan, J. F. Douglas, E. K. Lin, W.-L. Wu, S. K. Satija, D. L. Goldfarb, and M. Angelopoulos, 'Water immersion of model photoresists: interfacial influences on water concentration and surface morphology,' J. Microlith. Microfab. Microsyst. 4, 013003-1 (2005).

12 R. P. Berkelaar, P. Bampoulis, E. Dietrich, H. P. Jansen, X. Zhang, E. S. Kooij, D. Lohse, and H. J. W. Zandvliet, 'Water-Induced Blister Formation in a Thin Film Polymer,' Langmuir 31, 1017-1025 (2015).

13 C. M. Berger and C. L. Henderson, The effect of humidity 
on water sorption in photoresist polymer thin films Polymer 44, 21012108 (2003).

14 S. Kanna, H. Inabe, K. Yamamoto, T. Fukuhara, S. Tarutani, H. Kanda, W. Kenji, K. Kodama, and K. Shitabatake, 'Materials and process parameters study on ArF immersion defectivity,' Proc. SPIE 6153, 615308 (2006).

15 H. Jeong, J. Kyung, S. Park, K. Lee, H. Lee, H. Cheon, I. An, and S. Lee, 'Ellipsometric studies of the absorption of liquid by photo resist,' Proc. SPIE 6518, 651849 (2007).

16 J. C. Taylor, R. J. LeSuer, C. R. Chambers, F.-R. F. Fan, A. J. Bard, W. E. Conley, and C. G. Willson, 'Experimental Techniques for Detection of Components Extracted from Model $193 \mathrm{~nm}$ Immersion Lithography Photoresists,' Chem. Mater. 17, 4194-4203 (2005).

17 R. R. Dammel, G. Pawlowski, A. Romano, F. M. Hoolihan, W.-K. Kim, R. Sakmuri, D. Abdallah, M. Padmanaban, M. D. Rahman, and D. McKenzie, 'Leaching Phenomena and their Suppresion in $193 \mathrm{~nm}$ Immersion Lithography,' J. Photopolymer Sci. Technol. 18, 593-602 (2005).

18 R. Gronheid, E. Tenaglia, and M. Ercken, 'Dynamic leaching procedure on an immersion interference printer,' Proc. SPIE 6154, 61541I (2006).

19 S. Gaugiran, R. Feilleux, C. Sourd, S. Warrick, V. Farys, D. Cruau, M. Benndorf, and B. Mortini, 'Leaching mechanisms in immersion lithography with or without top coat,' Microelectron. Eng. 84, 1054-1057 (2007).

${ }^{20}$ S. H. Lee, J. W. Kim, J. W. Kim, S. K. Oh, C. S. Park, J. Y. Lee, S. S. Kim, J. W. Lee, D. Kim, J. Kim, K. D. Ban, C. K. Bok, and S. C. Moon, 'Polymer structure modifications for immersion leaching control,' Proc. SPIE 6519, 651925 (2007).

21 Y. Utsumi, Y. Komuro, A. Kawaue, T. Seshimo, H. Hada, T. Nakamura, Y. Yoshii, J. Onodera, and S. Ogawa, 'Study of PAG Material Design for ArF Immersion Photoresist,' J. Photopolymer Sci. Technol. 21, 719-723 (2008).

${ }^{22}$ H. V. Tran, E. Hendrickx, F. Van Roey, G. Vandenberghe, and R. H. French, 'Fluid-photoresist interactions and imaging in high-index immersion lithography,' J. Micro/Nanolith. MEMS MOEMS 8, 033006 (2009).

23 T. W. G. van der Heijden, A. A. Darhuber, and P. van der Schoot, 'Compound redistribution due to droplet evaporation on a thin polymeric film: Theory,' J. Appl. Phys. 126, 065303 (2019)

${ }^{24}$ C. Josserand and S. T. Thoroddsen, 'Drop Impact on a Solid Surface,' Annu. Rev. Fluid Mech. 48, 365-91 (2016).

25 A. B. Gardiner, A. Qin, C. L. Henderson, S. Pancholi, W. J. Koros, C. G. Willson, R. R. Dammel, C. Mack, and W. D. Hinsberg, 'Diffusivity Measurements in Polymers II: Residual Casting Solvent Measurement by Liquid Scintillation Counting,' Proc. SPIE 3049, 850-860 (1997).

${ }^{26}$ H. Nakagawa, A. Nakamura, H. Dougauchi, M. Shima, S. Kusumoto, and T. Shimokawa, 'Improvement of watermark defect in immersion lithography: mechanism of watermark defect formation and its reduction by using alkaline-soluble immersion topcoat,' Proc. SPIE 6153, 61531R (2006)

27 T. Hoskins, P. J. Roman, P. J. Ludovice, and C. L. Henderson, 'Equilibrium water uptake and diffusion behavior in model polynorbornene photoresist polymers,' Proc. SPIE 5753, 851 (2005)

${ }^{28}$ P. Foubert, M. Kocsis, R. Gronheid, S. Kishimura, A. Soyano, K. Nafus, N. Stepanenko, J. De Backer, N. Vandenbroeck, and M. Ercken, 'Measurement and Evaluation of Water Uptake by Resists, Top Coats and Stacks and
Correlation with Watermark Defects,' Proc. SPIE 6519, 65190E-1 (2007).

29 J. K. Park, J. Ryu, B. C. Koo, S. Lee and K. H. Kang, 'How the change of contact angle occurs for an evaporating droplet: effect of impurity and attached water films,' Soft Matter, 8, 11889 (2012).

30 A. A. Darhuber and S. M. Troian, 'Marangoni Driven Structures in Thin Film Flows,' Phys. Fluids 15, S9 (2003).

31 F. Wodlei, J. Sebilleau, J. Magnaudet, and V. Pimienta, 'Marangoni-driven flower-like patterning of an evaporating drop spreading on a liquid substrate,' Nature Communications $\mathbf{9}, 820$ (2018).

32 D. Brutin, 'Influence of relative humidity and nano-particle concentration on pattern formation and evaporation rate of pinned drying drops of nanofluids,' Coll. Surf. A: Physicochem. Eng. Aspects 429, 112-120 (2013).

${ }^{33}$ K. Sefiane, 'On the Formation of Regular Patterns from Drying Droplets and Their Potential Use for Bio-Medical Applications,' J. Bionic Eng. 7 Suppl., S82S93 (2010).

34 T. Niiyama and A. Kawai, 'Formation Factors of Watermark for Immersion Lithography,' Jpn. J. Appl. Phys. 45, 5383-5387 (2006).

35 R. D. Deegan, O. Bakajin, T. F. Dupont, G. Huber, S. R. Nagel, and T. A. Witten, 'Capillary flow as the cause of ring stains from dried liquid drops,' Nature 389, 827 (1997).

36 T. van der Heijden, A. A. Darhuber and P. van der Schoot, 'Macroscopic Model for Sessile Droplet Evaporation on a Flat Surface,' Langmuir 34, 12471-12481 (2018).

37 A. de Ryck and D. Quere, 'Fluid Coating from a Polymer Solution,' Langmuir 14, 1911-1914 (1998).

${ }^{38}$ H. M. J. M. Wedershoven, J. C. H. Zeegers, and A. A. Darhuber, 'Polymer film deposition from a receding solution meniscus: The effect of laminar forced air convection,' Chem. Eng. Sci. 181, 92-100 (2018).

39 W. Conley, R. J. LeSuer, F. F. Fan, A. J. Bard, C. Taylor, P. Tsiartas, G. Willson, A. Romano, R. Dammel, 'Understanding the Photoresist Surface-Liquid Interface for ArF Immersion Lithography,' Proc. SPIE 5753, 64 (2005).

40 B. He and A. A. Darhuber, 'Electrical Surface Charge Patterns Induced by Droplets Sliding over Polymer and Photoresist Surfaces,' J. Micromech. Microeng. 29, 105002 (2019).

41 B. Streefkerk, J. Mulkens, R. Moerman, M. Stavenga, J. van der Hoeven, C. Grouwstra, R. Bruls, M. Leenders, S. Wang, Y. van Dommelen, M. Boerema, H. Jansen, K. Cummings, M. Riepen, H. Boom, M. Suddendorf, and P. Huisman, 'A dive into clear water: immersion defect capabilities," Proc. SPIE 6154, 61540S (2006).

${ }^{42}$ Y. Wei, N. Stepanenko, A. Laessig, L. Voelkel, and M. Sebald, 'Evaluation of 193-nm immersion resist without topcoat,' J. Microlith., Microfab., Microsyst. 5, 033002 (2006).

43 J. Cantone, Y. van Dommelen, A. Jiang, S. Dunn, T. Winter, K. Petrillo, R. Johnson, P. Lawson, W. Conley, and R. Callahan, 'Defectivity issues in topcoatless photoresists,' J. Vacuum Sci. Technol. B 27, 3014 (2009).

${ }^{44}$ D. Kawamura, T. Takeishi, K. Sho, K. Matsunaga, N. Shibata, K. Ozawa, S. Shimura, H. Kyoda, T. Kawasaki, S. Ishida, T. Toshima, Y. Oonishi, and S. Ito, 'Influence of the watermark in immersion lithography process,' Proc. SPIE 5753, 818 (2005);

${ }^{45}$ M. Sado, T. Teratani, H. Fujii, R. Iikawa, and H. Iida, 'Influences of water on photoresist surface in immersion lithography technology,' Appl. Surf. Sci. 255, 1018-1021 
(2008)

46 B. M. Rathsack, S. Scheer, Y. Kuwahara, J. Kitano, R. Gronheid, and C. Baerts, 'Finite element modeling of PAG leaching and water uptake in immersion lithography resist materials," Proc. SPIE 6923, 692315 (2008).

47 T. Ishibashi, T. Hanawa, T. Suganaga, K. Narimatsu, K. Suko, M. Terai, T. Kumada, and T. Ando, 'Studies of the Mechanism for Immersion Specific Defects,' Proc. SPIE 6153, 61533I (2006).

48 V. Farys, S. Gaugiran, D. Cruau, K. Mestadi, S. Warrick, M. Benndorf, R. Feilleux, and C. Sourd, 'Investigation on Immersion Defectivity Root Cause,' Proc. SPIE 6533, 653308 (2007).

49 G. M. Wallraff, C. E. Larson, G. Breyta, L. Sundberg, D. Miller, D. Gil, K. Petrillo, and W. Pierson, 'The effect of photoresist/topcoat properties on defect formation in immersion lithography,' Proc. SPIE 6153, 61531M (2006).

50 P. Atkins and J. de Paula, 'Physical Chemistry', Oxford University Press (Oxford, 2006).

${ }^{51}$ M. L. Shulman, R. J. Charlson and E. J. Davis, 'The Effects of Atmospheric Organics on Aqueous Droplet Evaporation,' J. Aerosol Sci. 28, 737-752 (1997).

52 A. Jossang and E. Stange, 'A new predictive activity model for aqueous salt solutions,' Fluid Phase Equilibria 181, 3346 (2001).

${ }^{53}$ M. J. Blandamer, J. B. F. N. Engberts, P. T. Gleeson and J. C. R. Reis, 'Activity of water in aqueous systems; A frequently neglected property,' Chem. Soc. Rev. 34, 440458 (2005).

54 B.-B. Wang, X.-D. Wang, M. Chen, and J.-L. Xu, 'Molecular Dynamics Simulations on Evaporation of Droplets with Dissolved Salts,' Entropy 15, 1232-1246 (2013).

55 N. A. Combe and D. J. Donaldson, 'Water Evaporation from Acoustically Levitated Aqueous Solution Droplets,' J. Phys. Chem. A 121, 7197-7204 (2017).

56 J. Guadarrama-Cetina, R. D. Narhe, D. A. Beysens, and W. Gonzalez-Vinas, 'Droplet pattern and condensation gradient around a humidity sink,' Phys. Rev E 89, 012402 (2014).

57 L. Treuel, S. Schulze, Th. Leisner and R. Zellner, 'Deliquescence behaviour of single levitated ternary salt/carboxylic acid/water microdroplets,' Faraday Discuss. 137, 265-278 (2008).

58 L. J. Mauer and L. S. Taylor, 'Water-Solids Interactions: Deliquescence,' Annu. Rev. Food Sci. Technol. 1, 41-63 (2010).

59 X. Li, D. Gupta, H.-J. Eom, H. K. Kim, and C.-U. Ro, 'Deliquescence and efflorescence behavior of individual $\mathrm{NaCl}$ and $\mathrm{KCl}$ mixture aerosol particles,' Atmos. Environ. 82, 36-43 (2014).

60 I. N. Tang, 'Phase Transformation and Growth of Aerosol Particles Composed of Mixed Salts,' J. Aerosol Sci. 7, 361371 (1976).

61 R. P. Donovan, 'Why control humidity in a cleanroom?,' Solid State Technol. (2003).

${ }^{62}$ C.-H. Tsai, K.-Y. Chung, C.-M. Wang, 'Considerations for Cleanroom Control in Different Climatic Regions,' Proc. IEEE Semiconductor Manufacturing Technology Workshop (9-10 Sept. 2004, Hsinchu, Taiwan), p.59.

63 T. Tomita, T. Shimoaoki, M. Enomoto, H. Kyoda, J. Kitano, T. Suganaga, 'An investigation on defect-generation conditions in immersion lithography,' Proc. SPIE 6153, 61533M (2006).

${ }^{64}$ K. Matsunaga, T. Kondoh, H. Kato, Y. Kobayashi, K. Hayasaki, S. Ito, A. Yoshida, S. Shimura, T. Kawasaki, H. Kyoda, 'Defectivity reduction studies for ArF immersion lithography,' Proc. SPIE 6519, 65191T (2007).

${ }^{65}$ M. Kocsis, R. Gronheid, A. Soyano, P. Foubert, K. Nafus, M. Maenhoudt, N. Stepanenko, S. Kishimura, 'Watermark defects: underlying mechanisms and recommendations for their control,' 3rd International Symposium on Immersion Lithography (Kyoto, Japan, Oct. 2006). 